\title{
Obstetric and perinatal outcomes among women with blood- and injection phobia during pregnancy
}

Caroline Lilliecreutz, Gunilla Sydsjö and Ann Josefsson

\section{Linköping University Post Print}

N.B.: When citing this work, cite the original article.

Original Publication:

Caroline Lilliecreutz, Gunilla Sydsjö and Ann Josefsson, Obstetric and perinatal outcomes among women with blood- and injection phobia during pregnancy, 2011, Journal of Affective Disorders, (129), 1-3, 289-295.

http://dx.doi.org/10.1016/j.jad.2010.08.013

Copyright: Elsevier Science B.V., Amsterdam.

http://www.elsevier.com/

Postprint available at: Linköping University Electronic Press

http://urn.kb.se/resolve?urn=urn:nbn:se:liu:diva-59743 
Obstetric and perinatal outcomes among women with blood- and injection phobia during pregnancy

Caroline LILLIECREUTZ MD, Gunilla SYDSJÖ PhD, Ann JOSEFSSON MD, PhD

Department of Clinical and Experimental Medicine,

Division of Obstetrics and Gynaecology

Faculty of Health Sciences,

University of Linköping,

Sweden

Correspondence: C. Lilliecreutz MD

Division of Obstetrics and Gynaecology,

University Hospital,

SE-581 85 Linköping, Sweden.

tel: +46 132220 00; fax: +4613148156

E mail: caroline.lilliecreutz@lio.se 


\begin{abstract}
Background: Little is known about how anxiety disorders affect pregnancy outcomes.

Therefore we investigated the impact of one anxiety disorder, blood- and injection phobia, on obstetric and neonatal outcomes.

Methods: From a population-based prospectively collected cohort we compared an index group of 110 women with blood- and injection phobia with a control group of 220 women. Standardized medical records were used to collect data. Obstetric and neonatal outcomes e.g. elective cesarean, prematurity, and small for gestational age were used as the main outcome measures.
\end{abstract}

Results: Women with blood- and injection phobia stated more often a fear of childbirth $(p<0.001)$ and were more frequently delivered by elective cesarean section $(p=0.032)$. The incidence of premature delivery $(\mathrm{p}=0.028)$, neonatal morbidity $(\mathrm{p}=0.001)$ and the risk of having a baby born small for gestational age $(\mathrm{p}=0.009)$ was higher among women with bloodand injection phobia.

Limitations: The medical records, from which all information is drawn, despite standardization, sometimes may lack some information. However, this dilemma exists in both groups.

Conclusions: Women with an anxiety disorder such as blood- and injection phobia are at increased risk for adverse obstetric outcomes, premature delivery and for having a baby born with higher neonatal morbidity. It therefore seems important to identify and treat women with anxiety disorders without delay early during pregnancy in an effort to minimize risks of complications for the woman herself and the child.

Keywords: Anxiety, blood-and injection phobia, premature, small for gestational age, cesarean. 


\section{Introduction}

In the general population the most common anxiety disorder is to have a specific phobia, with a lifetime prevalence of approximately $8.7 \%$ (Kessler et al., 2005). The prevalence of bloodand injection phobia in an unselected pregnant population is $7 \%$ (Lilliecreutz and Josefsson, 2008). The blood- and injection phobia is the only specific phobia where the anxiety and sometimes panic attacks can result in fainting when the individual is exposed to the stimuli (Davey, 1997; Olatunji et al., 2006). Blood- and injection phobia during pregnancy might hypothetically create an intensive stress and anticipatory anxiety because of mandatory bloodsampling, and being in a health care environment facing the forthcoming delivery situation (Deacon and Abramowitz, 2006). Enquiries into the causes of maternal deaths in the United Kingdom indicate that women with injection phobia are at increased risk when exposed to anesthesia (Cooper and McClure, 2005). Blood- and injection phobia is also known to be associated with several co-morbid psychiatric conditions such as major depression, obsessivecompulsive disorder, panic disorder and posttraumatic stress disorder (PTSD) (Bienvenu and Eaton, 1998; Goisman et al., 1998). Maternal stress due to psychopathological factors such as depression and anxiety during pregnancy may constitute a risk for adverse pregnancy and perinatal outcomes (Alder et al., 2007; Li et al., 2009; Lou et al., 1994; O’Connor et al., 2002; Rodriguez and Bohlin, 2005). A recent study by Wisner concluded that continuous untreated depression in pregnant women was associated with preterm birth rates exceeding $20 \%$ (Wisner et al., 2009). Emerging research has also demonstrated that maternal stress during pregnancy can result in changes in the hypothalamic-pituitary-adrenal (HPA) axis and elevated levels of stress hormones (particularly cortisol) with premature labor, shortened pregnancy length, low birth weight and impaired fetal brain development as a consequence (Copper et al., 1996; Diego et al., 2006; Field et al., 2006; Gitau et al., 1998; Obel et al., 2005; Sandman et al., 1994; Wadhwa et al., 1993; Weinstock, 2005). In addition to the 
problems mentioned above, there is evidence that children born with low birth weight have more problems later in life with increased likelihood of corticoid sensitive disorders such as hypertension, cardiovascular diseases, dyslipidemia, type 2 diabetes and increased anxiety and exaggerated stress responses (Beltrand and Lévy-Marchal, 2008; Bonamy et al., 2008; Emack et al., 2008; Herbert et al., 2006).

In an earlier study, we have shown that pregnant women with blood- and injection phobia have more symptoms of depression and anxiety than healthy pregnant women and these women are therefore in a stressful situation (Lilliecreutz et al., 2010).

The hypothesis of this population-based prospective cohort study was that women with bloodand injection phobia constitute a group with an increased risk for adverse obstetric and neonatal outcomes because of the stress and anxiety faced during pregnancy. 


\section{Methods}

\section{Setting and participants}

The Swedish antenatal health care system reaches almost $100 \%$ of all pregnant women (The Swedish National Board of Health and Welfare 2007). The same percentage is valid for deliveries as there are no private maternity hospitals in the study area and home deliveries are rare. The antenatal care clinics provide regular check-ups on the physical and psychological health during pregnancy and puerperium.

At the antenatal care clinics, healthy pregnant women are advised to attend the regular antenatal program with seven to nine visits to a midwife and, if needed, extra appointments with an obstetrician and/or with the midwife. The first visit generally takes place around gestational weeks $10-12$.

The original sample in the present study comprises the total population of pregnant women consecutively registered at the antenatal care clinics in two counties in the southeast region of Sweden (Lilliecreutz and Josefsson, 2008). The counties cover a mixed sociodemographic structure with industrial, high technological, educational as well as farming areas. Enrolment took place during 2005.

\section{Study design}

The eligible women were approached in gestational weeks 12-16 and received both written and oral information about the screening procedures for anxiety and phobic symptoms by their midwife before giving consent. The only exclusion criterion was inability to understand Swedish. In the assessment of symptoms for blood- and injection phobia we used the "Injection Phobia Scale-Anxiety" (IPSA). IPSA consists of 18 items describing various anxiety provoking situations (Öst et al., 1992a). The woman rates the degree of anxiety in situations involving injections from 0 to 4 (scale range 0-72). Some examples of items included in the scale are: "Giving a blood sample by having a finger pricked, "Having a shot 
in the upper arm", and "Having a vein puncture". At threshold 20 the IPSA has a sensitivity of approximately $100 \%$ for blood- and injection phobia (Lilliecreutz and Josefsson, 2008). The internal consistency of the scale has been tested and has been found to be reliable (Cronbachs alpha 0.86) (Öst, 1992b). The IPSA is to be considered as a screening tool and not a diagnostic instrument.

A total of 1606 women were approached. Seventy seven (4.8\%) women declined to participate in the study. These women were similar in their geographic and age distribution to the participating women. Out of 1529 women, all women who scored $\geq 20$ on the IPSA (Öst et al., 1992a), in total 347, were interviewed by telephone and diagnosed or dismissed according to DSM-IV (DSM-IV 1994) for blood- and injection phobia. An experienced authorized psychotherapist (author GS) conducted the diagnostic interviews. In total, 110 women were diagnosed as having blood- and injection phobia. These women constitute the index group. Among the 1182 women scoring < 20 on the IPSA, 220 women were randomly stratified for age and parity as a control group for the index women. The randomization was done by a research assistant who, from the data sheet, randomly picked one control woman for each index woman among the feasible group of women considering age and parity. In order to verify that women scoring $<20$ on the IPSA do not suffer from blood- and injection phobia 25 women, randomly chosen in that particular group, were interviewed by telephone; none fulfilled the criteria according to DSM-IV for blood- and injection phobia (DSM-IV 1994; Lilliecreutz and Josefsson, 2008).

To assess the women's degree of anxiety, the Beck Anxiety Inventory (BAI) was used (Beck et al., 1988). In gestational week 25 both the women with blood- and injection phobia and the women in the control group were asked to complete the questionnaire. 


\section{Outcomes and potential confounding variables}

All data related to the pregnancy, delivery, and the puerperium were registered in the standardized Swedish antenatal, delivery and neonatal records.

The data were manually extracted from the records by the first author, and are thus prospectively collected. The following data were collected to receive information concerning outcome- and potential confounding variables: age, parity, marital status, occupation, prepregnancy Body Mass Index, smoking, drug abuse, number of induced abortions, miscarriages, or extrauterine pregnancies. Any history both past and current of psychiatric disorder (depression, anxiety disorders except blood- and injection phobia, eating disorder, psychotic disease), fear of childbirth or obstetric complications, actual chronic medical diseases (e.g. asthma with continuous need of pharmacological treatment, epilepsy, hypertension, rheumatic arthritis, inflammatory bowel disease and diabetes), pharmacological treatment, number of visits at the antenatal care clinics before delivery (midwife and obstetrician), pregnancy complications (preeclampsia, hyperemesis, back pain, vaginal bleeding and premature contractions), sick leave during pregnancy, and perinatal events including all relevant delivery data were obtained. The frequency of postnatal hospital stay exceeding 48 hours for the index women was compared with that of the control women. Neonatal morbidity was defined as a condition that generated a diagnosis on the baby and demanded a pediatrician's attention more often than simply at the time of the routine examination of the newborn for example jaundice, fever or hypoglycemia.

All women in the study had an ultrasound examination during the first trimester to determine the length of pregnancy.

Primiparas and multiparas are presented separately because of their differences as groups concerning the medical- obstetric- and gynecologic histories. 


\section{Statistics}

All analyses were done using the SPSS program 16.0 (SPSS Inc., Chicago, IL).

Significance was defined as two-sided $\mathrm{P}$ values using a significance level of 5\%.

When comparing the index and the control group we used the t-test for quantitative variables with approximately normal distribution. The Mann-Whitney tests were used when analyzing variables with asymmetric distribution (BAI) and the Chi-Square tests were used when analyzing the categorical variables.

Blood-and injection phobia, age, parity, marital status, socioeconomic group, BMI, smoking and psychiatric disorder were defined as independent factors.

Obstetric outcomes; (number of visits to midwife/obstetrician, preeclampsia, hyperemesis, back pain, vaginal bleeding, premature contractions, referral to a special unit for treatment because of fear of childbirth, sick leave, premature delivery, induction of labor, normal delivery, instrumental delivery, cesarean section, N2O, epidural anesthesia, puerperium complications and delivery in gestational week) and Neonatal outcomes; (neonatal morbidity, small for gestational age, congenital major malformation, postnatal hospital stay and breastfeeding) were defined as dependent factors.

SGA was defined as a birth weight less than two standard deviations below the mean weight for gestational length according to the Swedish standard (Marsal et al., 1996).

The possible effects of the independent factors were estimated through multiple logistic regression analyses to predict the probability of each possible obstetric and neonatal outcome due to blood-and injection phobia. Considering pharmacological treatment with antidepressants (particularly SSRIs) as a possible confounder in this study the use of these drugs in the study population was very low; one woman in the index group and two women in the control group were prescribed SSRI during pregnancy. The use of antidepressants was therefore not included as an independent factor in the statistical analysis. 
Univariate analysis of variance (UNIANOVA) was used for adjusting for the independent variables concerning the quantitative variable; delivery in gestational week.

When analyzing data concerning premature delivery (defined as being born at less than 37 completed weeks of gestation) the women with intrauterine fetal death (IUFD), twins and cesarean deliveries due to preeclampsia were excluded. IUFDs were also excluded when analyzing the data concerning small for gestational age (SGA). The incidence of IUFD was one case in each group. The reason for excluding the above mentioned cases was to eliminate their impact on the results concerning premature delivery and SGA as they are potential confounders. No adjustment for multiple comparisons was done.

\section{Ethics}

The study was approved by the regional Ethics Committee for Human Research of the Faculty of Health Sciences, Linköping University (No.192-04). 


\section{Results Baseline characteristics}

The distribution of the sociodemographic variables is shown in Table 1. Women with bloodand injection phobia (the index group) were over-represented in the lower socioeconomic groups. Obesity was also more common among the index women compared with the control women.

Primiparas with blood- and injection phobia did not differ from the women without bloodand injection phobia concerning gynecological and obstetric history (Table 2).

Multiparas with blood- and injection phobia had chronic medical diseases more often than multiparas without blood- and injection phobia $(\mathrm{p}=0.019)$ (table 3$)$, but the distribution of different actual chronic medical diseases did not differ between the groups. The chronic medical diseases that was presented amongst the two groups of women and that were considered to be potential confounders in this study were hypertension and inflammatory bowel disease. None of the women with these conditions delivered prematurely nor did they have a baby small for gestational age.

The multiparas with blood- and injection phobia had a history of having had more induced abortions than the control women (Table 3). Smoking in early pregnancy was more common among women with blood- and injection phobia $(\mathrm{p}=0.001)$ (Table 1) and this relationship was still evident after adjusting for sociodemographic variables and a history of psychiatric disorders $(\mathrm{p}=0.031)$.

\section{Relationship between blood- and injection phobia and obstetric/neonatal outcomes}

Fear of childbirth was significantly more frequent among women with blood- and injection phobia $(\mathrm{p}<0.001)$ (Table 4a) and was still evident after adjustment $(\mathrm{p}=0.001)$ (Table 4b). Pregnancy complications were in general equally distributed among the women in both groups (Table 4a). After analyzing specific conditions and adjusting for sociodemographic variables, smoking and a history of psychiatric disorders, complications like preeclampsia and 
Table 1. Sociodemographic Data for the study population

\begin{tabular}{|c|c|c|c|c|c|}
\hline & \multicolumn{2}{|c|}{ Index women } & \multicolumn{2}{|c|}{ Control women } & \multirow[b]{2}{*}{$\mathbf{p}^{*}$} \\
\hline & $\mathbf{n}$ & $\%$ & $\mathbf{n}$ & $\%$ & \\
\hline Age & & & & & 0.371 \\
\hline $16-24$ & 8 & 7.3 & 10 & 4.5 & \\
\hline $25-34$ & 84 & 76.4 & 163 & 74.1 & \\
\hline $35-46$ & 18 & 16.4 & 47 & 21.4 & \\
\hline Parity & & & & & 0.351 \\
\hline 0 & 53 & 49.1 & 120 & 54.5 & \\
\hline$\geq 1$ & 55 & 50.9 & 100 & 45.5 & \\
\hline Marital status & & & & & 0.219 \\
\hline Married/Cohabiting & 108 & 98.2 & 219 & 99.5 & \\
\hline Single mother & 2 & 1.8 & 1 & .5 & \\
\hline Socioeconomic groups & & & & & $<0.001$ \\
\hline Unemployed & 9 & 8.2 & 5 & 2.3 & \\
\hline Unskilled workers & 15 & 13.6 & 13 & 5.9 & \\
\hline Student/others & 19 & 17.3 & 18 & 8.2 & \\
\hline $\begin{array}{l}\text { Skilled/Lower white } \\
\text { collar workers }\end{array}$ & 48 & 43.6 & 101 & 45.9 & \\
\hline $\begin{array}{l}\text { Middle/high white collar } \\
\text { workers }\end{array}$ & 19 & 17.3 & 83 & 37.7 & \\
\hline BMI & & & & & $<0.001$ \\
\hline-24 & 63 & 57.8 & 145 & 66.5 & \\
\hline $25-29$ & 26 & 23.9 & 66 & 30.3 & \\
\hline 30- & 20 & 18.3 & 7 & 3.2 & \\
\hline Smoking & & & & & 0.001 \\
\hline No & 98 & 89.1 & 215 & 97.7 & \\
\hline Yes & 12 & 10.9 & 5 & 2.3 & \\
\hline
\end{tabular}


Table 2. Gynecological and Obstetric History for Primiparous women

\begin{tabular}{|c|c|c|c|c|c|}
\hline & Ind & men & Cont & omen & \\
\hline & $\mathbf{n}$ & $\%$ & & $\%$ & $\mathbf{p}^{*}$ \\
\hline $\begin{array}{l}\text { Chronic medical } \\
\text { disease }\end{array}$ & & & & & 0.083 \\
\hline No & 48 & 90.6 & 90 & 75.0 & \\
\hline Yes & 5 & 9.4 & 30 & 25.0 & \\
\hline Psychiatric disorder & & & & & 0.207 \\
\hline No & 43 & 81.1 & 106 & 88.3 & \\
\hline Yes & 10 & 18.9 & 14 & 11.7 & \\
\hline Induced abortions & & & & & 0.611 \\
\hline 0 & 42 & 79.2 & 99 & 82.5 & \\
\hline$\geq 1$ & 11 & 20.8 & 21 & 17.5 & \\
\hline Miscarriages & & & & & 0.925 \\
\hline 0 & 47 & 88.7 & 107 & 89.2 & \\
\hline$\geq 1$ & 6 & 11.3 & 13 & 10.8 & \\
\hline
\end{tabular}

premature contractions were more common among the women in the index group (Table $4 b$ ). The women with blood- and injection phobia were more likely to deliver premature $(\mathrm{p}=0.028)$ and were more often delivered with an elective cesarean section $(\mathrm{p}=0.032)$ (Table 5a). These differences remained in the multiple logistic regression analyses (Table 5b). Among multiparous women, $15 \%$ of those with blood- and injection phobia vs. $6 \%$ in the control group were delivered by means of an elective cesarean section and the corresponding figures among primiparous women were $4 \%$ vs. $2 \%$. The indications for the elective cesarean sections among the phobic women were registered in the medical records as "fear of childbirth“" (6 out of 10), breech presentation ( 2 out of 10) and previously fourth-degree perineal tear (2 out of 10). In the control group, none of the women were delivered by cesarean section because of fear of childbirth.

Children of mothers with blood- and injection phobia had a higher occurrence of neonatal morbidity $(\mathrm{p}=0.001)$, were more often born SGA $(\mathrm{p}=0.009)$ and had a longer postnatal 
Table 3. Gynecological and Obstetric History for Multiparous women

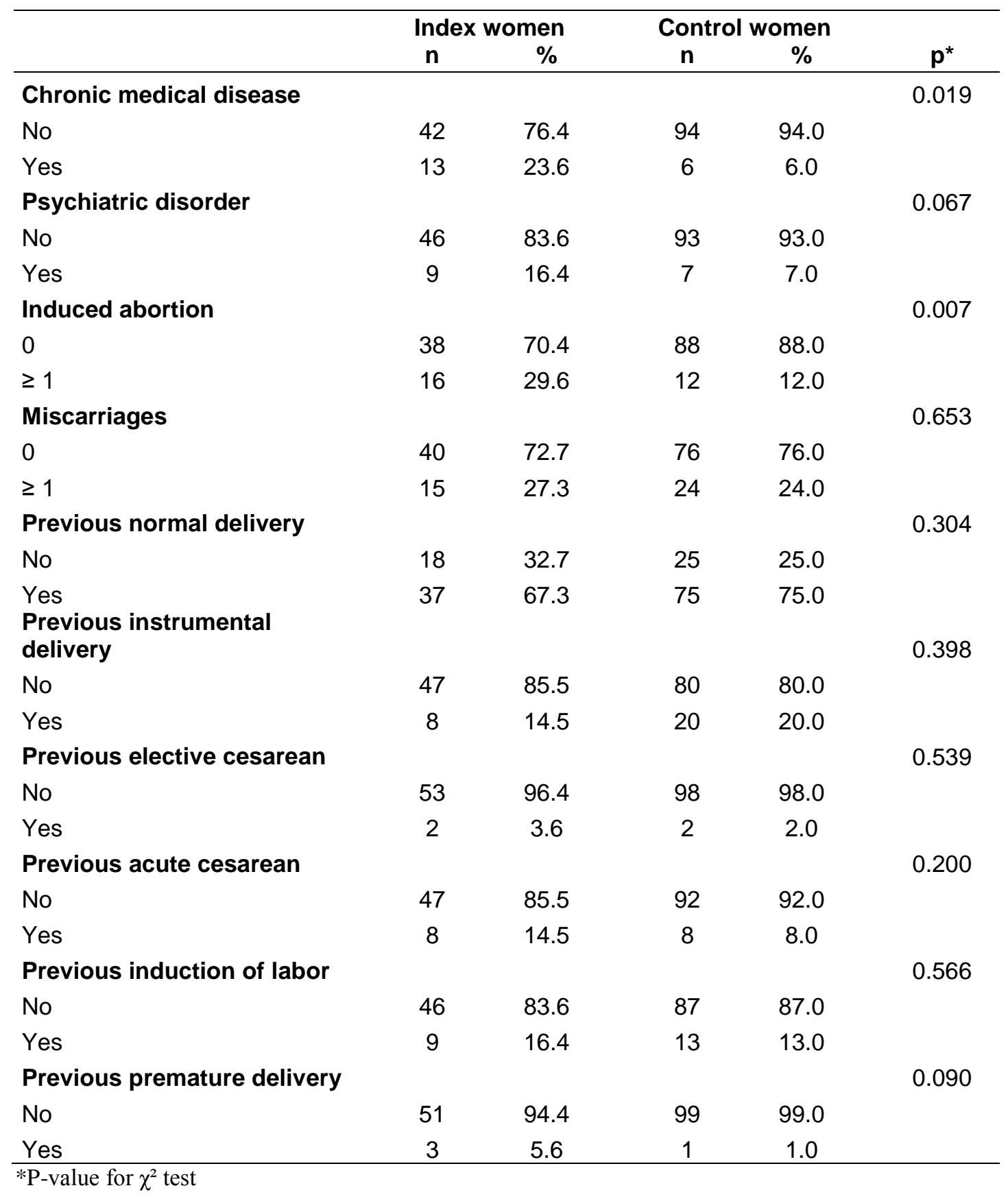

hospital stay $(\mathrm{p}=0.001)$ (Table 6a). When the multiple logistic regression analyses were performed these differences were still evident (Table 6b). 
Table 4a. Pregnancy Related Data

\begin{tabular}{|c|c|c|c|c|c|}
\hline & \multicolumn{2}{|c|}{ Index women } & \multicolumn{2}{|c|}{ Control women } & \multirow[b]{2}{*}{$\mathbf{p}^{\star}$} \\
\hline & $\mathbf{n}$ & $\%$ & $\mathbf{n}$ & $\%$ & \\
\hline \multicolumn{5}{|l|}{ Visits to midwife at the ANC } & \multirow{3}{*}{0.597} \\
\hline $1-8$ visits & 68 & 63.6 & 145 & 66.5 & \\
\hline$>8$ visits & 39 & 36.4 & 73 & 33.5 & \\
\hline \multicolumn{5}{|l|}{ Visits to physician at the ANC } & \multirow{3}{*}{0.457} \\
\hline$\leq 2$ visits & 100 & 93.5 & 208 & 95.4 & \\
\hline$\geq 3$ visits & 7 & 6.5 & 10 & 4.6 & \\
\hline \multicolumn{5}{|l|}{ Pregnancy complication } & \multirow[t]{3}{*}{0.885} \\
\hline No & 91 & 84.3 & 184 & 83.6 & \\
\hline Yes & 17 & 15.7 & 36 & 16.4 & \\
\hline \multicolumn{6}{|l|}{ Type of complication ${ }^{\dagger}$} \\
\hline Preeclampsia & 6 & 5.6 & 2 & .9 & 0.010 \\
\hline Hyperemesis & 5 & 4.7 & 8 & 3.7 & 0.659 \\
\hline Back pain & 35 & 32.7 & 57 & 26.0 & 0.208 \\
\hline Vaginal bleeding & 10 & 9.3 & 13 & 5.9 & 0.259 \\
\hline Premature contractions & 15 & 14.0 & 20 & 9.1 & 0.181 \\
\hline \multicolumn{5}{|l|}{$\begin{array}{l}\text { Referred to special unit for } \\
\text { treatment because of fear of } \\
\text { childbirth }\end{array}$} & \multirow[t]{3}{*}{0.001} \\
\hline No & 95 & 86.4 & 213 & 96.8 & \\
\hline Yes & 15 & 13.6 & 7 & 3.2 & \\
\hline Sick- leave & & & & & 0.652 \\
\hline No & 85 & 78.7 & 177 & 80.8 & \\
\hline Yes & 23 & 21.3 & 42 & 19.2 & \\
\hline
\end{tabular}

$\mathrm{ANC}=$ Antenatal care clinic *P-value for $\chi^{2}$ test

${ }^{\dagger}$ A woman can have more than one pregnancy complication 
Table 4b. Risk for Pregnancy-Related Conditions among women with blood- and injection phobia (index women) compared to women without blood- and injection phobia (control women) adjusted for socio-demographic factors, smoking and a history of psychiatric disorder

\begin{tabular}{|c|c|c|c|c|}
\hline & OR & \multicolumn{2}{|c|}{$95 \% \mathrm{Cl}$} & $p$ \\
\hline$>8$ visits to midwife at the ANC & 1.29 & 0.73 & -2.26 & 0.380 \\
\hline $\begin{array}{l}>2 \text { visits to physician at the } \\
\text { ANC }\end{array}$ & 1.16 & 0.34 & -3.96 & 0.816 \\
\hline Pregnancy complication & 0.69 & 0.30 & -1.58 & 0.377 \\
\hline Preeclampsia & 10.39 & 1.84 & 58.56 & 0.008 \\
\hline Hyperemesis & 0.88 & 0.23 & -3.32 & 0.853 \\
\hline Back pain & 1.38 & 0.77 & -2.46 & 0.278 \\
\hline Vaginal bleeding & 1.78 & 0.69 & -4.62 & 0.234 \\
\hline Premature contractions & 2.48 & 1.07 & -5.76 & 0.035 \\
\hline $\begin{array}{l}\text { Referred to special unit for } \\
\text { treatment because of fear of } \\
\text { childbirth }\end{array}$ & 6.60 & 2.20 & - 19.79 & 0.001 \\
\hline Sick-leave & 0.97 & 0.50 & 1.85 & 0.920 \\
\hline
\end{tabular}

OR = Odds Ratio

$\mathrm{CI}=$ Confidence Interval 
Table 5a. Delivery-Related data

\begin{tabular}{|c|c|c|c|c|c|c|c|}
\hline & $\begin{array}{c}\text { Index } \\
\text { women } \\
\text { n }\end{array}$ & $\%$ & & $\begin{array}{c}\text { Control } \\
\text { women } \\
n\end{array}$ & $\%$ & & $\mathbf{p}^{*}$ \\
\hline Premature delivery & & & & & & & 0.028 \\
\hline No & 102 & 92.7 & & 215 & 97.7 & & \\
\hline Yes & 8 & 7.3 & & 5 & 2.3 & & \\
\hline Induction of labor & & & & & & & 0.916 \\
\hline No & 95 & 89.6 & & 198 & 90.0 & & \\
\hline Yes & 11 & 10.4 & & 22 & 10.0 & & \\
\hline Normal delivery & & & & & & & 0.468 \\
\hline No & 30 & 28.3 & & 54 & 24.5 & & \\
\hline Yes & 76 & 71.7 & & 166 & 75.5 & & \\
\hline Instrumental delivery & & & & & & & 0.715 \\
\hline No & 94 & 88.7 & & 198 & 90.0 & & \\
\hline Yes & 12 & 11.3 & & 22 & 10.0 & & \\
\hline Acute cesarean section & & & & & & & 0.363 \\
\hline No & 97 & 91.5 & & 194 & 88.2 & & \\
\hline Yes & 9 & 8.5 & & 26 & 11.8 & & \\
\hline Elective cesarean section & & & & & & & 0.032 \\
\hline No & 96 & 90.6 & & 212 & 96.4 & & \\
\hline Yes & 10 & 9.4 & & 8 & 3.6 & & \\
\hline $\mathrm{N}_{2} \mathrm{O}$ & & & & & & & 0.895 \\
\hline No & 20 & 18.9 & & 40 & 18.3 & & \\
\hline Yes & 86 & 81.1 & & 179 & 81.7 & & \\
\hline Epidural anesthesia & & & & & & & 0.541 \\
\hline No & 71 & 67.0 & & 154 & 70.3 & & \\
\hline Yes & 35 & 33.0 & & 65 & 29.7 & & \\
\hline $\begin{array}{l}\text { Puerperium without } \\
\text { complications }\end{array}$ & & & & & & & 0.315 \\
\hline No & 9 & 11.3 & & 14 & 7.5 & & \\
\hline \multirow[t]{2}{*}{ Yes } & 71 & 88.8 & & 173 & 92.5 & & \\
\hline & $\mathbf{n}$ & Mean & Sd & $\mathbf{n}$ & Mean & Sd & $\mathbf{p}^{\star \star}$ \\
\hline Delivery in gestational week ${ }^{\ddagger}$ & 96 & 39.1 & 2.2 & 212 & 39.5 & 1.8 & 0.079 \\
\hline
\end{tabular}


Table 5b. Risk for Delivery-Related Conditions among women with blood- and injection phobia (index women) compared to women without blood- and injection phobia (control women) adjusted for socio-demographic factors, smoking and a history of psychiatric disorder.

\begin{tabular}{|c|c|c|c|c|}
\hline & OR & & $5 \% \mathrm{Cl}$ & $\mathbf{p}^{*}$ \\
\hline Premature delivery & 3.58 & 1.01 & -12.67 & 0.047 \\
\hline Induction of labor & 1.02 & 0.44 & -2.40 & 0.956 \\
\hline Normal delivery & 0.72 & 0.39 & -1.31 & 0.280 \\
\hline Instrumental delivery & 1.75 & 0.75 & - 4.07 & 0.194 \\
\hline Acute cesarean section & 0.59 & 0.23 & -1.51 & 0.272 \\
\hline Elective cesarean section & 4.43 & 1.52 & -12.96 & 0.007 \\
\hline $\mathrm{N}_{2} \mathrm{O}$ & 0.94 & 0.48 & -1.81 & 0.841 \\
\hline Epidural anesthesia & 1.40 & 0.79 & -2.96 & 0.253 \\
\hline Puerperium without complications & 0.71 & 0.26 & 1.99 & 0.518 \\
\hline Delivery in gestational week (mean $(s d))^{\ddagger}$ & Unianova & - & - & 0.081 \\
\hline
\end{tabular}

When comparing the results from the BAI conducted in gestational week 25 the women with blood- and injection phobia $(\mathrm{n}=74$, mean=10.06, SD 7.2) scored higher than the control group $(\mathrm{n}=145$, mean 7.32, SD 8.87), $\mathrm{p}<0.001$. 
Table 6a. Perinatal data

\begin{tabular}{|c|c|c|c|c|c|}
\hline & Inde) & omen & Contr & vomen & \\
\hline & $\mathbf{n}$ & $\%$ & $\mathbf{n}$ & $\%$ & $\mathbf{p}^{*}$ \\
\hline Neonatal morbidity & & & & & 0.001 \\
\hline No & 81 & 77.1 & 198 & 90.4 & \\
\hline Yes & 24 & 22.9 & 21 & 9.6 & \\
\hline $\begin{array}{l}\text { Small for gestational } \\
\text { age SGA }\end{array}$ & & & & & \\
\hline No & 105 & 95.5 & 219 & 99.5 & 0.009 \\
\hline Yes & 5 & 4.5 & 1 & 0.5 & \\
\hline $\begin{array}{l}\text { Congenital major } \\
\text { malformation }\end{array}$ & & & & & 0.520 \\
\hline No & 99 & 94.3 & 210 & 95.9 & \\
\hline Yes & 6 & 5.7 & 9 & 4.1 & \\
\hline Postnatal hospital stay & & & & & 0.001 \\
\hline 1-2 days & 42 & 41.2 & 134 & 61.8 & \\
\hline$>2$ days & 60 & 58.8 & 83 & 38.2 & \\
\hline Breast-feeding & & & & & 0.063 \\
\hline No & 14 & 17.9 & 18 & 9.7 & \\
\hline Yes & 64 & 82.1 & 167 & 90.3 & \\
\hline
\end{tabular}


Table 6b. Risk for perinatal conditions among women with blood- and injection phobia (index women) compared to women without blood- and injection phobia (control women) adjusted for socio-demographic factors, smoking and a history of psychiatric disorder

\begin{tabular}{lccc}
\hline & OR & $95 \% \mathbf{C l}$ & $\mathbf{p}^{\star}$ \\
\hline Neonatal morbidity & 3.16 & $1.55-6.46$ & 0.002 \\
$\begin{array}{l}\text { Small for gestational age } \\
\text { (SGA) }\end{array}$ & 6.45 & $1.052-39.50$ & 0.044 \\
$\begin{array}{l}\text { Congenital major } \\
\text { malformation }\end{array}$ & 1.16 & $0.34-3.97$ & 0.811 \\
$\begin{array}{l}\text { Postnatal hospital stay } \\
\text { Breast-feeding }\end{array}$ & 3.10 & $1.74-5.53$ & $0.000^{\star \star}$ \\
& 0.87 & $0.36-2.12$ & 0.759
\end{tabular}

OR $=$ Odds Ratio

$\mathrm{CI}=$ Confidence Interval

*P-values adjusted for socio-demographic variables, smoking and a history of psychiatric disorder

** P-values adjusted for socio-demographic variables, smoking, a history of psychiatric disorder and cesarean delivery 


\section{Discussion}

In this population-based prospective cohort study, we observed that women with blood- and injection phobia have a higher risk for an adverse obstetric (preeclampsia, premature contractions, fear of childbirth, premature delivery and elective cesarean), and neonatal outcome (neonatal morbidity, to give birth to a SGA child and postnatal hospital stay). Unsurprisingly, in addition to the diagnosis of blood- and injection phobia the women in the index group scored higher on the BAI in gestational week 25 compared to the controls; this finding strengthens our line of reasoning that these women suffer from more anxiety than the healthy women without blood- and injection phobia.

The women in this study were all routinely managed at the antenatal care clinics, and the attendance rate of meeting with their midwives was the same for both groups of women, which means that despite any social disadvantage, medical or psychiatric disease, the level of pregnancy care and surveillance has been the same in the two groups. Another advantage of this study is the fact that we had reached the total pregnant population at the time of the study and that data were prospectively collected and later extracted from standardized medical records and not from maternal recall. The number of women who declined to participate in the original study was also low $(4.8 \%)$.

A potential weakness is that the medical records, from which all information is drawn, sometimes may lack some information despite the high level of standardization. However, this problem exists in both groups, i.e. women could be more willing to talk about chronic medical problems than they are about induced abortions, smoking or psychiatric problems.

The high frequency of fear of childbirth partly explains the higher rate of elective cesarean section for the index women. In this study elective cesareans are more common among multiparous women compared to the women who gave birth to their first child. The reason for 
the difference in elective cesarean rate between multi- and primiparas might be due to the fact that those phobic women who already had experienced a delivery refused to go through the same procedure once more because of a negative experience; the phobia could also provoke more anxiety and even panic attacks in these women facing a second delivery.

The decision to have an elective cesarean section is based on more than medical factors alone; factors such as local traditions and women's opinions and requests that might play an important role. All these considerations can limit the implications of applying these results outside of Sweden.

The women with blood- and injection phobia had a longer postnatal hospital stay than those in the control group, even after controlling for the higher rate of elective cesarean section, which might be explained by the higher rate of complications such as preeclampsia or neonatal morbidity. The finding of a higher rate of premature delivery among the phobic women in our study adds to previous findings that stress and anxiety during pregnancy might also have an impact on gestational length and thus result in premature birth (Federenko and Wadhwa, 2004).

Children born in the blood- and injection phobic group of women have a higher risk for being SGA. This agrees with earlier studies that have shown that children born of mothers with a high degree of anxiety and stress during their pregnancy have a low birth weight (Diego et al., 2006; Federenko and Wadhwa, 2004). Maternal stress during pregnancy has also been shown in several studies to have a significant association with emotional problems in children and it even appears to be one of the determinants of delay in motor and mental development in infants 8 months of age (Huizink et al., 2003; Rice et al., 2007). Other findings in this study are that the women with blood- and injection phobia also constitute a socially more disadvantaged and vulnerable group. 
The multiparous women with blood- and injection phobia also had a history of more induced abortions, which might be explained by fear of childbirth or a previous delivery experience that could have reinforced the blood- and injection phobia or even led to a development of the phobia. The phobic women's less privileged socioeconomic background could also be of importance when they face an unwanted pregnancy.

As previously reported in the literature, we also found an association between having an anxiety disorder and a physical disorder; the multiparous women with blood- and injection phobia had more chronic medical diseases than the controls (Kose and Mandiracioglu, 2007; Sareen et al., 2005). The distribution of actual chronic medical diseases that affect outcomes did not differ between the groups and was therefore not considered as an independent variable in the multiple regression analyses.

Our hypothesis that women with an anxiety disorder such as blood- and injection phobia constitute a group with an increased risk for adverse obstetric and neonatal outcomes was partly confirmed as the results showed that these women are at a higher risk of developing preeclampsia, of premature delivery, and having a baby born SGA. The absolute numbers for preeclampsia, preterm deliveries and SGA babies was under 10 in both groups. In the statistical analysis these above mentioned variables comes with broad confidence intervals which makes the true clinical importance of this finding hard to interpret. Further and larger studies are therefore needed to confirm our results.

Pregnant women with blood- and injection phobia are more likely to be delivered by elective cesarean section and having a baby born with a complication compared to women not suffering from this specific phobia. These new findings may have important clinical implications. With the above findings in mind it seems important to recognize this group of women in early pregnancy and to offer an effective treatment for blood- and injection phobia 
without delay in an effort to minimize risks of complications for the woman herself and the child.

\section{Role of the funding source}

This study was supported by grants from The Health Research Council in the SouthEast of Sweden. The council had no involvement in the study.

\section{Conflict of interest}

All authors declare that they have no financial or other competing interests.

\section{Acknowledgements}

We thank statistician MA Marie Bladh for valuable statistic assistance. This study was supported by grants from The Health Research Council in the SouthEast of Sweden. 


\section{References}

Alder J, Fink N, Bitzer J, Hosli I, Holzgreve W (2007) Depression and anxiety during pregnancy:a risk factor for obstetric, fetal and neonatal outcome? A critical review of the literature. J. Matern. Fetal. Neonatal. Med. 20:189-209

Beck AT, Epstein N, Brown G, Steer RA (1988) An inventory for measuring clinical anxiety: Psychometric properties. J. Consult. Clin. Psychol. 56: 893-897

Beltrand J, Lévy-Marchal C (2008) Pathophysiology of insulin resistance in subjects born small for gestational age. Best. Pract. Res. Clin. Endocrinol. Metab. 22:503-515

Bienvenu OJ, Eaton WW (1998) The epidemiology of blood-injection-injury phobia. Psychol. Med. 28:1129-1136

Bonamy AK, Norman M, Kaijser M (2008) Being Born Too Small, Too Early, or Both: Does it Matter for Risk of Hypertension in the Elderly. Am. J. Hyperten. 21:1107-1110 Copper RL, Goldenberg RL, Das A, Elder N, Swain M, Norman G, Ramsey R, Cotroneo P, Collins BA, Johnson F, Jones P, Meier AM (1996) The preterm prediction study: maternal stress is associated with spontaneous preterm birth at less than thirty-five weeks' gestation. National Institute of Child Health and Human Development MaternalFetal Medicine Units Network. Am. J. Obstet. Gynecol. 175:1286-1292 Cooper GM, McClure JH (2005) Maternal death from anaesthesia. An extract from Why Mothers Die 2000-2002, the Confidential Enquiries into Maternal Deaths in the United Kingdom: Chapter 9: Anaesthesia. Br. J. Anaesth. 94:417-423 Davey GCL (1997) Phobias. A handbook of theory, research and treatment. Sussex, England: Wiley.

Deacon B, Abramowitz J (2006) Fear of needles and vasovagal reactions among phlebotomy patients. Anxiety Disord. 20: 946-960 
Diego MA, Jones NA, Field T, Hernandez-Reif M, Schanberg S, Kuhn, C, GonzalezGarcia A (2006) Maternal psychological distress, prenatal cortisol and fetal weight. Psychosom. Med. 68:747-753

DSM-IV 1994: Diagnostic and Statistic Manual of Mental Disorders, fourth edition, American Psychiatric Association.

Emack J, Kostaki A, Walker CD, Matthews SG (2008). Chronic maternal stress affects growth, behaviour and hypothalamic-pituitary function in juvenile offspring. Horm.

Behav. 54: 514-520

Federenko IS, Wadhwa PD (2004) Women's mental health during pregnancy influences fetal and infant developmental and health outcomes. CNS Spectr..9:198-206

Field T, Hernandez-Reif M, DiegoM, Figueiredo B, Schanberg S, Kuhn C (2006) Prenatal cortisol, prematurity and low birthweight. Infant. Behav. Dev. 29:268-275

Gitau R, Cameron A, Fisk NM, Glover V (1998) Fetal exposure to maternal cortisol. The Lancet 352:707-708

Goisman RM, Allsworth J, Rogers MP, Warshaw MG, Goldenberg I, VasileRG,

Rodriguez-Villa F, Mallya G, Keller MB (1998) Simple phobia as a comorbid disorder.

Depress.. Anxiety 7:105-112

Herbert J, Goodyer IM, Grossman AB, Hastings MJ, de Kloet ER, Lightman SL, Lupien

SJ, Roozendaal B, Seckl JR (2006) Do corticosteroids damage the brain? J.

Neuroendocrinol. 18: 393-411

Huizink AC, Robles de Medina PG, Mulder EJH, Visser GHA, Buitelaar JK (2003) Stress during pregnancy is associated with developmental outcome in infancy. J. Child. Psychol. Psychiatry 44:810-818 
Kessler RC, Chiu WT, Demler O, Walters E E (2005) Prevalence, Severity, and Comorbidity of 12-Month DSM-IV Disorders in the National Comorbidity Survey Replication. Arch. Gen. Psychiatry 62:617-27

Kose S, Mandiracioglu A (2007) Fear of blood/injection in healthy and unhealthy adults admitted to a teaching hospital. J. Clin. Pract. 61:453-457

Li D, Liu L, Odouli R (2009) Presence of depressive symptoms during early pregnancy and the risk of preterm delivery: a prospective cohort study. Hum.. Reprod.. 24:146-153 Lilliecreutz C, Josefsson A (2008) Prevalence of blood and injection phobia among pregnant women. Acta. Obstet. Gynecol. Scand. 87:1276-1279

Lilliecreutz C, Josefsson A, Sydsjö G (2010) An open trail with cognitive behavioural therapy for blood-and injection phobia in pregnant women- a group intervention program. Arch. Womens. Ment. Health 13:259-65

Lou HC, Hansen D, Nordenfoft M, Pryds O, Jensen F, Nim J, Hemmingsen R (1994) Prenatal stressors of human life affect fetal brain development. Dev. Med. Child. Neurol. 36: $826-832$

Marsal K, Persson PH, Larsen T, Lilja H, Selbing A, Sultan B (1996) Intrauterine growth curves based on ultrasonically estimated foetal weights. Acta. Paediatr. 85:843-848 Obel C, Hedegaard M, Henriksen TB, Secher NJ, Olsen J, Levine S (2005) Stress and salivary cortisol during pregnancy. Psychoneuroendocrinology 30:647-656 O’Connor TG, Heron J, Glover V, for the Alspac Study Team (2002) Antenatal anxiety predicts child behavioral/emotional problems independently of postnatal depression. J. Am. Acad. Child. Adolesc. Psychiatry 41:1470-1477

Olatunji BO, Williams NL, Sawchuk CN, Lohr JM (2006) Disgust, anxiety and fainting symptoms associated with blood-injection-injury fears: a structural model. J. Anxiety Disord. 20:23-41 
Rice F, Jones I, Thapar A (2007) The impact of gestational stress and prenatal growth on emotional problems in offspring: a review. Acta Psychiatr. Scand. 115:171-83

Rodriguez A, Bohlin G (2005) Are maternal smoking and stress during pregnancy related to ADHD symptoms in children? J. Child. Psychiatry 46:246-54

Sandman CA, Wadhwa PD, Dunkel-Schetter C, Chicz-DeMat A, Belman J, Porto M, Murata Y, Garite TJ, Crinella FM ( 1994) Psychobiological influences of stress and HPA regulation on the human fetus and infant birth outcomes. Ann. NY Acad. Sci. 739:198210

Sareen J, Cox BJ, Clara I, Asmundson GJG (2005) The relationship between anxiety disorders and physical disorders in the U.S. national comorbidity survey. Depress. Anxiety 21:193-202

The Swedish National Board of Health and Welfare.2007. The Centre for Epidemiology. Available at: http://www.sos.se/epc/epceng.htm. Retrieved 10 April 2009.

Wadhwa PD, Sandman CA, Porto M, Dunkel-Schetter C, Garite TJ (1993) The association between prenatal stress and infant birth weight and gestational age at birth: a prospective investigation. Am. J. Obstet. Gynecol. 169:858-865

Weinstock M (2005) The potential influence of maternal stress hormones on development and mental health of the offspring. Brain Behav. Immun. 19: 296-308

Wisner KL, Sit DK, Hanusa BH, Moses-Kolko EL, Bogen DL, Hunker DF, Perel JM, Jones-Ivy S, Bodnar LM, Singer LT (2009) Major Depression and antidepressant treatment: impact on pregnancy and neonatal outcomes. Am. J. Psychiatry 166: 557-566 Öst L-G, Hellström K, Kåver A (1992 a) One versus five session of exposure in the treatment of injection phobia. Behav. Ther. 23:263-282

Öst L-G, (1992b) Blood and injection phobia: background and cognitive, physiological and behavioral variables. J. Abnorm. Psychol. 101:68-74 